BIOKEMISTRI 18(1):39-44 (June 2006)

Available online at http://www.bioline.org. br/bk

and at http://www.aiol.info/journals/biokem

Printed in Nigeria

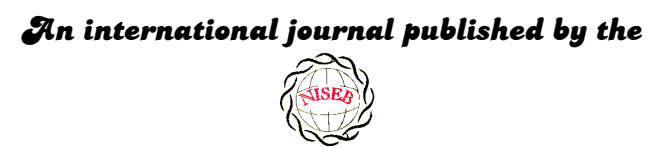

OVigerian \&ociety for \&̊xperimental \$iology

\title{
Phytochemical screening and antimicrobial assessment of Abutilon mauritianum, Bacopa monnifera and Datura stramonium
}

\section{Aderotimi BANSO ${ }^{1 *}$ and Samuel ADEYEMO}

${ }^{1}$ Department of Science Laboratory Technology, The Federal Polytechnic, P.M.B. 55, Bida, Niger State, Nigeria.

${ }^{2}$ Department of Biological Sciences, Bowen University, Iwo, Nigeria

Received January 25, 2006

MS/No BKM/2005/042, ㄷ 2006 Nigerian Society for Experimental Biology. All rights reserved.

\begin{abstract}
Three medicinal plants - Abutilon mauritianum, Bacopa monnifera and Datura stramonium were assessed for phytochemical components and antimicrobial activity. The results revealed that all the three plant extracts contained saponins, tannins and alkaloids. Only Datura stramonium contained glycosides. The plants exert varying inhibitory effects on Pseudomonas aeruginosa, Klebsiella pneumonia and Escherichia coli. The minimum inhibitory concentration of the plant extracts ranged between 10\% (w/v) (Bacopa monnifera) and 25\% (w/v) (A. mauritianum and D. stramonium). Extracts of Abutilon mauritianum, Bacopa monnifera and Datura stramonium could be potential sources of chemotherapeutic agents.
\end{abstract}

Keywords: Phytochemical, antimicrobial, chemotherapeutic agent.

*To whom correspondence should be addressed. Tel: 08060775952, 08045028829 


\section{INTRODUCTION}

Plants are rich in a variety of secondary metabolites such as tannins, terpenoids, alkaloids, flavonoids, phenols, steroids, glycosides and volatile oils ${ }^{1}$. It is necessary to identify the phytochemical components of local medicinal plants usually employed by herbalists in the treatment of diseases, especially now that there are proposals on the integration of traditional medicine in health care programme in Nigeria. In addition, investigations into antimicrobial activities of local medicinal plants will expose the plants as potential sources of therapeutic agents ${ }^{2}$. The volatile oils of black pepper (Piper nigrum L.) were assessed for antibacterial activity ${ }^{3}$. The stem bark extracts of Enantia chloranta showed antimicrobial activity against some bacteria ${ }^{4}$. The antibacterial and antifungal activities of Zanthoxylum budrungia has been reported ${ }^{5}$.

The use of chemotherapeutic agents in the treatment of infectious diseases has been known from time immemorial. The ancient man discovered the therapeutic value of some herbs by trial and error ${ }^{6}$. The alternative use of folkloric medicinal plants detailed their alternative use in medicine in Jamaican society has been studied ${ }^{7}$. The effective inhibition of the growth of some Gram-positive and Gramnegative bacteria by the chloroform and ethyl acetate extracts of Nyctanthes arbortritis fresh flowers has been reported ${ }^{8}$.

Datura stramonium is an erect branched undershrub with long white flowers and spiny spherical fruits ${ }^{9}$. Abutilon mauritianum and Bacopa monnifera are erect branched plants. The leaves of abutilon mauritianum is prescribed for diarrhoea gonorroea and bronchitis. The decoction of Bacopa monnifera is given as a febrifuge and cardiac tonic ${ }^{10}$.

The aims of this study are to identify the phytochemical components of Abutilon mauritianum (African Mallow), Bacopa monnifera (Thyme) and Datura stramonium (Stink weed) and to determine the antimicrobial effects of the plants extracts on Psedomonas aeruginosa, klebsiella pneumonia and Escherichia coli. Pseudomonas aeruginosa attaches to and colonises the mucous membranes or skin, invades locally and produces systemic diseases ${ }^{19}$. The bacterium is resistant to many antimicrobial agents. $K$. pneumoniae causes chest, urinary and wound infections. E. coli is the most common causes of urinary tract infection $^{19}$.

\section{MATERIALS AND METHODS}

\section{Plants Materials and Microorganisms}

The representative microorganisms used were Pseudomonas aeruginosa, Klebsiella pneumonia and Escherichia coli. They are medically important. The organisms were obtained from the culture collection centre, Department of Biological Sciences, University of Ilorin. The microorganisms were tested for purity by culturing on nutrient agar and maintained on nutrient agar slants. Leaves of Abutilon maritianum, Bacopa monnifera and Datura stramonium used in this study were obtained from The Federal Polytechnic, Bida, Niger State. Identification was carried out at the Herberium Unit of Department of Biological Sciences, University of Ilorin, Nigeria according to the criteria stipulated by International Committee for Botanical Nomenclature.

\section{Preparation of leaf extract}

Ethanol was very effective in extracting the active ingredients in the plants used in this study. Hence the organic solvent (ethanol) was used as the extracting solvent in this study. Ten grammes of ground dry leaf samples of the three plants were soaked in $250 \mathrm{ml}$ of $95 \%$ ethanol contained in three separate $500 \mathrm{ml}$ capacity flasks. The flasks were plugged with cotton wool, wrapped in aluminium foil, shaken vigorously and allowed to stand in the refrigerator for 24 hours. The extract obtained were evaporated to dryness using a rotary evaporator and stored in refrigerator in reagent bottles $^{11}$. Each extract was tested for growth/contamination by plating them on nutrient agar at $37^{\circ} \mathrm{C}$ for 24 hours. No growth was observed visually and the extract was subsequently used to assay for antimicrobial activity using the agar diffusion method. The percentage yield of the extract was determined using the expression:

Percentage yield $=\frac{\text { Weight of Extract }}{\text { Weight of ground plant Material }} \times 100$ 


\section{Phytochemical screening of Extract}

The methods described by Odebiyi and Sofowora ${ }^{12}$ were used to test for the presence of saponins, tannins, alkaloids, flavonoids and glycosides in the test samples.

\section{a. Determination of saponins}

Each of the plant extracts $(0.5 \mathrm{~g})$ was separately stirred in a test tube, foaming which persisted on warming was taken as an evidence for the presence of saponins ${ }^{12}$.

\section{b. Determination of tannins}

Ethanolic extract of each sample $(0.5 \mathrm{~g})$ was separately stirred with $10 \mathrm{ml}$ of distilled water and then filtered. To the filtrate was added two drops of $5 \%$ Iron (III) Chloride $\left(\mathrm{FeCl}_{3}\right)$ reagent. Blue - black or blue - green colouration or precipitate was taken as an indication of the presence of tannins ${ }^{12}$.

\section{c. Determination of alkaloids}

Extract of each plant sample $(0.5 \mathrm{~g})$ was separately stirred with $1 \%$ hydrochloric acid $(\mathrm{HCl})$ on a steam bath. The solution obtained was filtered and $1 \mathrm{ml}$ of the filtrate was treated with two drop of Mayer's reagent. The two solutions were mixed and made up to $100 \mathrm{ml}$ with distilled water. Turbidity of the extract filtrate on addition of Mayer's reagent was regarded as evidence for the presence of alkaloids in the extracts ${ }^{12}$.

\section{d. Determination of glycosides}

Coarsely powered plant material (1g) was introduced into two different beakers. To one of the beakers was added Sulphuric acid $(5 \mathrm{ml})$ while water $(5 \mathrm{ml})$ was added to the other beaker. The two beakers were heated for 3 minutes and the contents filtered into labelled test tubes. The filtrate was made alkaline with sodium hydroxide $(0.5 \mathrm{ml})$ and allowed to stand for three minutes. The presence of reddish brown precipitate in the filtrate was taken as positive for glycosides ${ }^{12}$.

\section{e. Determination of flavonoids}

To ethanolic extract of each piece of test plant leaf extract was added a small piece of magnesium ribbon, this was followed by dropwise addition of concentrated hydrochloric acid. Colours ranging from orange to red indicated flavones, red to crimson indicated flavonols, crimson to magenta indicated flavonones ${ }^{12}$.

\section{Antimicrobial Test}

This was performed using the agar diffusion method of Boakye-Yiadom ${ }^{13} \mathrm{P}$. aeruginosa, $K$. pneumonia or $E$. coli was inoculated on nutrient agar plate and spread uniformly using a glass spreader. A sterilised calibrated Pasteur pipette was used to introduce different concentrations $5 \%(\mathrm{w} / \mathrm{v}), 10 \%(\mathrm{w} / \mathrm{v})$, $15 \%(\mathrm{w} / \mathrm{v}), 20 \%(\mathrm{w} / \mathrm{v}), 25 \%(\mathrm{w} / \mathrm{v})$ and $30 \%$ $(\mathrm{w} / \mathrm{v})$ of the extracts into the wells bored onto the surface of the culture. Control experiments with no plant extracts were set up.

The plates were allowed to stand for one hour at room temperature to allow the diffusion of the substances to proceed before the growth of organism commenced. The plates were finally incubated at $37^{\circ} \mathrm{C}$ for $24 \mathrm{hrs}$.

\section{Determination of minimum inhibitory concentration (MIC) of the Extracts}

The plant extracts $(5 \mathrm{mg} / \mathrm{ml}, 10 \mathrm{mg} / \mathrm{ml}$, $20 \mathrm{mg} / \mathrm{ml}, \quad 25 \mathrm{mg} / \mathrm{ml}$ and $30 \mathrm{mg} / \mathrm{ml}$ ) were introduced into different test tubes, each tube was inoculated with an overnight culture $P$. aeruginosa, $K$. pneumonia or E. coli diluted to give a final concentration of $10^{6}$ cells per $\mathrm{ml}$. The tubes were incubated at $37^{\circ} \mathrm{C}$ for 24 hours. The lowest concentration of the plant extracts that did not permit any visible growth of the inoculated test organism in broth culture was regarded as the MIC in each case ${ }^{14}$.

\section{RESULTS AND DISCUSSION}

The phytochemical analysis of the plants assayed in this study revealed that $A$. mauritianum, B. monnifera and D. stramonium contained saponins, tannins and alkaloids (Table $1)$.

The antimicrobial activity of leaf extract of Eugenia uniflora was reported by Adebayo et $a l^{18}$. The authors also reported that tannins, glycosides and akaloids were present and that the ethyl acetate and methanolic leaf extracts of the plant were active against E. coli, $P$. vulgaris, $\mathrm{K}$. pneumonia and A. niger. All parts of the plants were strongly intoxicant and narcotic. Leaves of the plants were burnt and the smoke inhaled for the relief of asthma and cough ${ }^{10}$. The decoction of the leaves of Abutilon mauritianum is prescribed for diarrhoea, gonorrhoea 
inflammation, bronchitis and catarrhal condition $^{10}$. A hot poutice of Bacopa monnifera is applied in bronchitis and chest ailments of children $^{10}$.

Table 1: Phytochemical components of leaves of plants.

\begin{tabular}{|c|c|c|c|}
\hline $\begin{array}{l}\text { Chemical } \\
\text { constituent }\end{array}$ & $\begin{array}{l}A . \\
\text { mauritianum }\end{array}$ & $\begin{array}{l}\text { B. } \\
\text { monnifera }\end{array}$ & $\begin{array}{l}\text { D. } \\
\text { stramonium }\end{array}$ \\
\hline Saponins & + & \pm & \pm \\
\hline Tannins & + & \pm & + \\
\hline Alkaloids & ++ & + & ++ \\
\hline glycosides & - & - & \pm \\
\hline Flavonoids & + & - & - \\
\hline \multicolumn{4}{|c|}{$\begin{array}{l}+=\text { Positive }++=\text { Strongly positive; } \pm=\text { Trace } ; \\
-=\text { Not detected; Percentage yield of extracts: A. } \\
\text { mauritianum }=38 \% ; \text { D. stramonium }=35 \%, B . \\
\text { monnifera }=37 \%\end{array}$} \\
\hline
\end{tabular}

Saponins are a special class of glycosides which have soapy characteristics ${ }^{15}$. It has also been shown that saponins are active antifungal agents ${ }^{16}$. This therefore supports the earlier finding that extracts of the plants used in the present work may be useful in the chemotherapy of mycotic infections. Tannins have been reported to prevent the development of microorganisms by precipitating microbial protein and making nutritional proteins unavailable for them ${ }^{16}$. Classes of alkaloids are among the major powerful poisons known ${ }^{15}$. Apart from being poisonous, some alkaloids have also been proved to be useful in correcting renal disdorders ${ }^{17}$; it therefore, means that the alkaloids of $A$. mauritianum, B. monnifera and $D$. stramonium may be a poison that can be tried on lower or higher organisms. The secondary metabolites identified in the plant materials used in this study could be responsible for antimicrobial activity exhibited by these plants.

Table 2: Antimicrobial effects of different plant extracts

\begin{tabular}{|c|c|c|c|c|c|c|c|c|c|}
\hline \multirow{3}{*}{$\begin{array}{c}\text { Conc } \\
\% \\
\text { w/v }\end{array}$} & \multicolumn{9}{|c|}{ Mean diameter of zone of inhibition $(\mathrm{mm}) \pm \mathrm{SD}$} \\
\hline & \multicolumn{3}{|c|}{ A. mauritianum } & \multicolumn{3}{|c|}{ B. monnifera } & \multicolumn{3}{|c|}{ D. stramonium } \\
\hline & $\mathbf{P v}$ & $\mathbf{K p}$ & Ec & $\mathbf{P v}$ & $\mathbf{K p}$ & Ec & $\mathbf{P v}$ & $\mathbf{K p}$ & Ec \\
\hline 5 & 0 & 0 & 0 & 0 & 0 & 0 & 0 & 0 & 0 \\
\hline 10 & 0 & 0 & 0 & 0 & $9.0 \pm 0.1$ & 0 & 0 & 0 & 0 \\
\hline 15 & 0 & $9.5 \pm 0.1$ & 0 & 0 & 10.0 & 11.0 & 8.0 & 0 & 0 \\
\hline 20 & $9.5 \pm 0.1$ & $11.5 \pm 0.2$ & 0 & $8.5 \pm 0.2$ & $13.0 \pm 0.1$ & $13.0 \pm 0.02$ & $10.0 \pm 0.01$ & 0 & $8.5 \pm 0.1$ \\
\hline 25 & $10.0 \pm 0.01$ & $12.0 \pm 0.1$ & $9.5 \pm 0.2$ & $9.0 \pm 0.1$ & $13.0 \pm 0.1$ & $15.0 \pm 0.1$ & $12.0 \pm 0.1$ & $9.0 \pm 0.1$ & $9.0 \pm 0.1$ \\
\hline 30 & $11.5 \pm 0.1$ & $12.0 \pm 0.1$ & $11.0 \pm 0.1$ & $9.0 \pm 0.2$ & $14.0 \pm 0.2$ & $15.0 \pm 0.1$ & $13.0 \pm 0.1$ & $11.0 \pm 0.2$ & $9.0 \pm 0.2$ \\
\hline
\end{tabular}

It was recorded that an increase in the concentration of extracts yielded higher activity as shown by the diameter of zone of inhibition (Table 2). The fact that organisms may need higher concentration of extracts to inhibit growth or kill them may depend on their cell wall components. Antimicrobial substances may affect the synthesis of peptidoglycan around a bacterial cell, the cell will die by osmotic shock. The minimum inhibitory concentration (MIC) of the plant extracts ranged between $10 \%(\mathrm{w} / \mathrm{v})$ and $25 \%(\mathrm{w} / \mathrm{v})$ (Table 3).
Table 3: Minimum Inhibitory Concentration (\% w/v) of plant extracts

\begin{tabular}{lccc}
\hline \multicolumn{1}{c}{ Plant } & P. aeruginosa & K. pneumonia & E. coli \\
\hline A. mauritianum & 20 & 15 & 25 \\
B. monnifera & 20 & 10 & 15 \\
D. stramonium & 15 & 25 & 20 \\
\hline
\end{tabular}

Note: The organisms used in Table 3 are medically important organisms 
The results of the MIC of the test extracts on the test organisms varied widely in the degree of their susceptibility. Antimicrobial agents with low activity against an organism have a high MIC while a highly active antimicrobial agent gives a low MIC.

\section{CONCLUSION}

Ethanolic leaf extract of $A$. mauritianum, $B$. monnifera, and D. stramonium exhibited antibacterial activity against $P$. aeruginosa $K$. pneumonia and E. coli. Possible antimicrobial substances contained in the extracts included alkaloids, saponins, tannins, flavonoids and glycosides. It therefore suggests that constituents of the plant extracts could serve as a source of drugs useful in the chemotherapy of some microbial infections.

\section{REFERENCES}

1. Cowan, M. M. (1999) Plant products as antimicrobial agents. Clin. Microbiol. Rev. 12:564- 582 .

2. Ebena, R. V., Madunaju, R. E., Ekpe, E. D and Itugu I. (1991) Microbiological exploitation of Cardiac-glycosides and alkaloid from Garcina kola, Bonveria ocymoides, Kola nitida and Citrus aurantifolia. J. Appl. Bacteriol. 71: 398 - 401.

3. Dorman, H. J. and Deans, S. G. (2000) Antimicrobial agents from plants: antibacterial activity of plant volatile oils. J. Appl. Microbiol. 88: $308-316$.

4. Atata, R. F. and Sani, A. (2003) Effect of stem bark extracts of Enantia chloranta on some clinical isolates. Biokemistri 15:84-92

5. Islam, A., Sayeed, A., Bhuiyan, M. S. A., Mosaddik, M. A., Islam, M. A. U., Astaq M., Khan, G. R. M. (2001) Antimicrobial activity and cytotoxicity of Zanthoxylum budrunga. Fitoterapia 72:428-430.

6. Sofowora, A. E (1993) Medicinal Plants and Traditional Medicine in Africa. 2nd Edn. Spectrum Books Ltd, Ibadan, Nigeria.
7. Facey, P. C., Pascoe, K.O., Porter, R. B and Jones A. D (1999) Investigation of plant used in Jamaican folk medicine for antibacterial activity. J. Pharm. Pharmacol 51:1455-1460.

8. Khatune, N. A., Modsnaddik, M. A. and Haque, M. E (2001) Antibacterial activity and cytotoxicity of Nyctanthes arbor - tristis flowers. Fitoterapia 72: 412- 414

9. Oliver, B. (1960) Medicinal plants of Nigeria. Publication of Nigeria College of Science and Technology, Ibadan Nigeria. Pp.20

10. Gill, L. S (1992) Ethnomediccal uses of plants in Nigeria. University of Benin Press, Benin City, Nigeria Pp.10-30

11. Akinyanju, J. A., Owoyale, J. and Okanla, E. O. (1986) Antimicrobial effect of leaf extract of Acalypha torta. In: The State Medicinal Plant Research in Nigeria, University of Ife Press, Ife Nigeria.

12. Odebiyi, O. O. and Sofowora, E. A. (1978) Phytochemical screening of Nigerian Medical Plants II Lloydia 41:2234-246.

13. Boakye-Yiadom, K. (1979) Antimicrobial properties of some West African Medicinal Plants II Antimicrobial activity of Aqueous Extracts of Crytolepsis sanguinolenta. Lind Schelecter Quart. J. Crude Drug Res 170:78-80.

14. Ressel, A. D and Furr, J. R. (1977) Antibacterial activity of new choloroxlenol preparation containing ethylene diamine tetracetic acid. J. Appl. Bacteriol. 43:253-260.

15. Fluck, H (1973) Medicinal plants and their uses. W. Feulshom and comp. Ltd, New York. Pp. 7-15.

16. Sodipo, O. A., Akanji, M. A., Kolawole, F. B., Odutuga, A. A. (1991) Saponin is the active antifungal principle in Garcinia kola, heckle seed, Biosci. Res. Commun. 3:171.

17. Konkwara J. O. (1976) Medicinal Plants of East Africa. Literature Burea, Nairobi. Pp 3-8. 
18. Adebayo, A. G., Oloke, J. K. and Aladesanmi, A. J. (1989) Antimicrobial activities of the leaf extract of Eugenia uniflora. Phytothera Res. 3:258-259.

19. Brooks, G.F; Butel, J.S and Morse, S.A (1998) Medical mycology. In: Jawets,
Melnicks and Adelberg's Medical Microbiology $5^{\text {th }}$ edition. Appleton and Lange A. Simon and Schister company, Prentice Hall International (UK) Limited, London Pp223-234. 